Article

\title{
Impact of Mycorrhization on Phosphorus Utilization Efficiency of Acacia gummifera and Retama monosperma under Salt Stress
}

\author{
Abdessamad Fakhech ${ }^{1}$, Martin Jemo ${ }^{2}$, Najat Manaut ${ }^{1}$, Lahcen Ouahmane ${ }^{1}$ and Mohamed Hafidi ${ }^{1,2, *}$ \\ 1 Laboratory of Microbial Biotechnologies, Agrosciences and Environment, Faculty of Science Semlalia, \\ Cadi Ayyad University, Marrakesh 40000, Morocco; abdessamad.fakhech@edu.uca.ac.ma (A.F.); \\ manaut_najat@yahoo.fr (N.M.); ouahamane@uca.ac.ma (L.O.) \\ 2 AgroBiosciences Program, Mohammed VI Polytechnic University (UM6P), Lot 660, Hay Moulay Rachid, \\ Ben-Guerir 43150, Morocco; Martin.JEMO@um6p.ma \\ * Correspondence: hafidi@uca.ac.ma
}

Citation: Fakhech, A.; Jemo, M.;

Manaut, N.; Ouahmane, L.; Hafidi, M. Impact of Mycorrhization on

Phosphorus Utilization Efficiency of Acacia gummifera and Retama monosperma under Salt Stress. Forests 2021, 12, 611. https://doi.org/ $10.3390 /$ f12050611

Academic Editor: Stefan Arndt

Received: 22 March 2021

Accepted: 29 April 2021

Published: 13 May 2021

Publisher's Note: MDPI stays neutral with regard to jurisdictional claims in published maps and institutional affiliations.

Copyright: (c) 2021 by the authors. Licensee MDPI, Basel, Switzerland. This article is an open access article distributed under the terms and conditions of the Creative Commons Attribution (CC BY) license (https:/ / creativecommons.org/licenses/by/ $4.0 /)$.

\begin{abstract}
The impact of salt stress on the growth and phosphorus utilization efficiency (PUE) of two leguminous species: Retama monosperma and Acacia gummifera was studied. The effectiveness of arbuscular mycorrhizal fungi (AMF) to mitigate salt stress was furthermore assessed. Growth, N and $\mathrm{P}$ tissue concentrations, mycorrhizal root colonization frequency and intensity, and $\mathrm{P}$ utilization efficiency (PUE) in the absence or presence of AMF were evaluated under no salt $\left(0 \mathrm{mM} \mathrm{L}^{-1}\right)$ and three salt $(\mathrm{NaCl})$ concentrations of $\left(25,50\right.$ and $\left.100 \mathrm{mM} \mathrm{L}^{-1}\right)$ using a natural sterilized soil. A significant difference in mycorrhizal colonization intensity, root-to-shoot ratio, P uptake, PUE, and N uptake was observed between the legume species. Salt stress inhibited the shoot and root growth, and reduced $\mathrm{P}$ and $\mathrm{N}$ uptake by the legume species. Mycorrhizal inoculation aided to mitigate the effects of salt stress with an average increase of shoot and root growth responses by $35 \%$ and $32 \%$ in the inoculated than in the non-inoculated $A$. gummifera treatments. The average shoot and root growth responses were $37 \%$ and $45 \%$ higher in the inoculated compared to the non-inoculated treatments of R. monosperma. Average mycorrhizal shoot and root P uptake responses were $66 \%$ and $68 \%$ under A. gummifera, and $40 \%$ and $95 \%$ under R. monosperma, respectively. Mycorrhizal inoculated treatments consistently maintained lower PUE in the roots. The results provide insights for further investigations on the AMF conferred mechanisms to salt stress tolerance response by A. gummifera and R. monosperma, to enable the development of effective technologies for sustainable afforestation and reforestation programs in the Atlantic coast of Morocco.
\end{abstract}

Keywords: arbuscular mycorrhizal fungi (AMF) consortium; Atlantic dunes forest; growth and uptake responses; leguminous species; reforestation program

\section{Introduction}

Acacia gummifera and Retama monosperma are two important legume species considered for afforestation and reforestation programs in the Atlantic coast of Morocco [1]. Due to their exhibited differences in water stress tolerance, rapid adaptation to poor available nutrient soil conditions, in particular nitrogen and phosphorus, these two leguminous species are gradually integrated in the afforestation and reforestation activities in replacement of Juniperus phoenicea with increasing tree mortality during transplantation stages [1]. However, successful plant establishment and growth development are hampered by various abiotic stresses, particularly drought and salinity, and therefore reduce the effectiveness of efforts by local authorities towards sustainable forest management [1,2].

Salt stress is among the major environmental problems affecting global agricultural production and sustainable utilization of land resources, particularly in arid and semiarid regions. About $7 \%$ of the Earth's land surface area is estimated to be affected by salt stress [3,4]. Excess of $\mathrm{Na}^{+}$and $\mathrm{Cl}^{-}$ions in the soil above the concentration of $12 \mathrm{~g} / \mathrm{L}$ is considered as highly saline, and depresses the growth of plants via osmotic stress, 
ionic toxicity, nutritional imbalance, and induces oxidative damages $[5,6]$. At the cellular level, the physiological and biochemical processes involved in plant growth, such as photosynthesis, protein synthesis, energy transfer, and lipid metabolism are negatively impacted by osmotic stress [4,6,7]. Salt stress impairs the seedling development and affects uptake of nutrients, in particular phosphorus, leading to a loss in crop productivity [8,9]. In response to a particular stress, plants develop several tolerance mechanisms that involve the overexpression of defense genes, root-to-shoot ratio modification, over salt extrusion and/or osmotic regulation process [10-12], allowing them, on one hand, to modify their morphological, physiological, and molecular behaviors to adapt a response [11-13].

On the other hand, plant roots' association with beneficial microorganisms such as plant growth-promoting rhizobacteria (PGPR) and arbuscular mycorrhizal fungi (AMF) improve their growth, mineral nutrition, health, and help to cope with adverse abiotic stresses $[2,14,15]$. The role of AMF in the mitigation of excessive salt stress has been reviewed $[2,8,9]$. AMF induces the expression of genes involved in the extrusion of $\mathrm{Na}+$ from cell to the soil, by improving the plant $\mathrm{K}^{+}$acquisition, release into the xylem, and maintenance of a favorable $\mathrm{Na}^{+}: \mathrm{K}^{+}$ratio under salt stress [16-18]. Mycorrhized plants also differentially modulate the transcriptional levels of chloroplast genes encoding antenna proteins involved in the transfer of energy excitation to maintain sufficient photosystemII (PSII) system, and boosts quantum efficiency of PSII under salt stress more than the non-mycorrhizal plants $[12,13]$. Furthermore, mycorrhiza fungi induce the interplay of phytohormones, including strigolactones, abscisic acid, gibberellic acid, salicylic acid, and jasmonic acid associated with the salt tolerance mechanism [19]. Mycorrhizal represents an integral component of soil ecosystems that is increasingly recognized as essential for sustainable forest ecology and management $[20,21]$.

Due to increasing mortality from Juniperus phoenicea, establishment at the field stage, A. gummifera and R. monosperma are being considered for the afforestation and reforestation programs [1,22], because of their important ecosystem services, in particular biological nitrogen fixation, carbon sequestration [23,24], soil protection against erosion [25], woods, and food provision to rural communities [26]. Furthermore, they offer a large plasticity to adapt to harsh climatic conditions. Despite their numerous above-mentioned beneficial contributions, the effect of salinity on growth development, phosphorus utilization efficiency (PUE), and physiological adjustments have not been adequately investigated [1,22]. For various crops such as maize (Zea mays L), sorghum (Sorghum bicolor), rice (Oryza sativa), and alfalfa (Medicago sativa) grown under salt stress conditions, the PUE was inhibited at a high salt concentration $[2,17,18,27]$.

The objectives of the present study were: (1) to assess the effects of salt stress on the growth and nutrient uptake behavior of two legume species, and (2) to evaluate the effect of AMFs in the mitigation of salt stress of A. gummifera and R. monosperma trees. Through rapid root colonization by AMF and their accessibility to nutrients, we hypothesize that AMF can help A. gummifera and R. monosperma seedlings to mitigate the salt stress and reduce their mortality to enable and promote rapid afforestation and reforestation activities in the Atlantic coast of Morocco region.

\section{Materials and Methods}

\subsection{Biological Materials}

\subsubsection{Seeds}

Seeds of R. monospermic and A. gummifera were obtained from the Centre Régional de la Recherche Forestière (CRRF), Marrakesh. Seeds of R. monospermic and A. gummifera were floated in tap water and $40 \%$ sucrose solution to remove dead seeds and other organic particles, then surface sterilized using $1 \%$ sodium hypochlorite for $5 \mathrm{~min}$, before rinsing repeatedly with distilled water before germination. 


\subsubsection{Mycorrhizal Inoculum}

A collection of mycorrhizal isolates belonging to Acaulospora and Entrophospora and Claroideoglomus genera was used. The AMF species were obtained from the Laboratory of Microbial Biotechnologies, Agrosciences and Environment, Marrakesh, Morocco. These inocula were previously tested for the beneficial effect to alleviate drought and salt stress [28]. To reach the required concentration of AMF spores in the inoculum, a trap culture using maize plants after 90 days of culture was established. The spores from AMF were isolated and maintained in sterile substrate formed by a mixture of sand and vermiculite $(1: 1, \mathrm{v}: \mathrm{v})$ using maize host plants before their inoculation. The final inoculum contained a spore density of 1, 9, and 15 spores/g of soil Acaulospora sp., Entrophospora sp. and Claroideoglomus sp., in addition to the mycelial fragments of AMF tested as recommended by [28].

\subsection{Experimental Soil and Design}

The soils used to establish the experiment were collected under the forest plantation of J. phoenicea located in the southeast region of Essaouira (31.2946 N, 9.4228 W). These soils were chosen as representative habitat under which A. gummifera and R. monosperma trees are being established. In the sampled site, 20 random sites were selected, and $15 \mathrm{~kg}$ of sampled soils collected at 5-50 $\mathrm{cm}$ depth at each site, bulked to a composite soil sample and transferred to the greenhouse. The soil was air-dried and sterilized, and $3 \mathrm{~kg}$ of dried and bulk soil was filled in $4 \mathrm{~L}$ plastic pots and placed in the greenhouse.

The experiment was setup in a randomized complete block design with three factors tested: Factor 1: leguminous (L) species at 2 levels (R. monosperma and A. gummifera); factor 2: mycorrhiza (M) inoculation at 2 levels [in the absence or presence of $A M F$ ], and factor 3: salt (S) treatments at 4 concentration levels $\left(0-, 25-, 50-\right.$ and $\left.100-\mathrm{mM} \mathrm{L}^{-1} \mathrm{NaCl}\right)$ Five replicates were used for each treatment. Five seeds of approximately $1 \mathrm{~cm}$ size of the $R$. monosperma and A. gummifera were germinated and seedlings between $4-5 \mathrm{~cm}$ length were transplanted per pot and later thinned to two plants per pot until harvest at 180 days after transplanting. Plants were watered and maintained at $75 \%$ field capacity at daily intervals and randomly arranged and kept under greenhouse, with the following growing conditions: day/night temperatures set at $25.5^{\circ} \mathrm{C} / 17^{\circ} \mathrm{C}$, a relative humidity of $68.5 \%$ and $16 / 8 \mathrm{~h}$ light/dark photoperiod. The positions of pots in the greenhouse were randomly re-arranged at weekly intervals to ensure homogeneity in received light and radiation. Shoot and root fresh matter, total shoot-N and -P concentrations, and root colonization levels by AMF were measured at harvest.

\subsection{Salt Stress Treatment}

Sodium chloride $(\mathrm{NaCl})$ was used for the salinity treatment. Four concentrations of $\mathrm{NaCl}$ were applied: $0-, 25-, 50-$, and $100-\mathrm{mM} \mathrm{L}^{-1}$. After transplanting of $R$. monosperma and A. gummifera seedlings, exogenous $\mathrm{NaCl}$ was supplied to the nutrient solution at the different $25-, 50-$ and $100-\mathrm{mM} \mathrm{L}^{-1}$ concentrations and added in the respective pots. To avoid percolation and osmotic shock, the nutrient solution was supplied in 4 subdivided applications and supplied at 10-day interval periods.

\subsection{Mycorrhizal Treatment}

The AMF treatments received the native mycorrhizal consortia of Acaulospora sp., Entrophospora sp. and Claroideoglomus sp. Inoculation was performed by adding $10 \mathrm{~g}$ of fresh inoculum containing root fragments and spores as close as possible to the roots during seedling transplantation.

\subsection{Measurements}

\subsubsection{Levels of Mycorrhizal Root Colonization Frequencies and Intensities}

The intensity and the frequency of root colonization by AMF were measured using a procedure modified by [29] and [30]. Fragments of roots were macerated in $10 \%(\mathrm{w} / \mathrm{v})$ $\mathrm{KOH}$ at $90{ }^{\circ} \mathrm{C}$ for $1 \mathrm{~h}$, then neutralized with $1 \% \mathrm{HCl}$ for $20 \mathrm{~min}$ at room temperature, 
stained with Trypan and Methylene Blue (0.05\% each in lactoglycerol) at $90{ }^{\circ} \mathrm{C}$ for $15 \mathrm{~min}$, and de-stained in water overnight. Root segments were mounted onto slides, and the frequency and intensity of colonization by AMF observed under a microscope at $200 \times$ magnification using an Olympus AX70 microscope (Olympus-Japan, Tokyo, Japan).

The level of mycorrhization colonization frequency (MCF) was determined following [31] procedure's (Equation (1)):

$$
\operatorname{MCF}(\%)=\frac{\text { number of colonized root fragments }}{\text { number of total root fragments analyzed }} \times 100
$$

The mycorrhization colonization intensity (MCI) was determined using the following Equation (2):

$$
\operatorname{MCI}(\%)=\frac{(95 n 5+70 n 4+30 n 3+5 n 2+n 1)}{\text { Total roots segments }}
$$

The mycorrhizal index was assigned from 0 to 5, where 0 represents no colonization, "n1": traces of colonization (0-1\%), "n2", colonization rate from 1-10\%, "n3", colonization rate between $11-50 \%$, " $n 4$ ": colonization rate from $51-90 \%$, and " $\mathrm{n} 5$ ": colonization rate from 91 to $100 \%$, respectively [32].

\subsubsection{Shoot and Root Biomass Dry Matter (DM)}

At 180 days after transplanting, shoots were collected, and their fresh matter (FM) was recorded. Subsequently, the shoot samples were oven-dried at $70{ }^{\circ} \mathrm{C}$ for $72 \mathrm{~h}$, and their dry matter (DM) was recorded. The roots were gently washed to remove the soil and the FM of roots was measured. Lastly, fresh roots were oven-dried at $70{ }^{\circ} \mathrm{C}$ for $72 \mathrm{~h}$, and their DM was measured.

\subsubsection{Elemental Analyses}

Subsamples of dry shoot and root matter were finely crushed and passed through a $1 \mathrm{~mm}$ mesh, and then $0.5 \mathrm{~g}$ of each sample was digested in concentrated $\mathrm{H}_{2} \mathrm{SO}_{4}$ at $500{ }^{\circ} \mathrm{C}$. The concentrations of $\mathrm{N}$ in the extracts were measured according to the method described by [33]. The concentrations of $P$ in the extracts were measured by the colorimetric procedure of [34]. The total P accumulated in shoots (leaves plus stalks) and roots was calculated by multiplying the $\mathrm{P}$ concentration and dry matter of each plant portion. The $\mathrm{P}$ utilization efficiency (PUE) in shoots and roots was calculated as a ratio between the dry matter weight, and $\mathrm{P}$ concentration in shoot or root, expressed $\mathrm{g} \mathrm{DM} \mathrm{mg}^{-1} \mathrm{P}$ following the [35] procedures. Mycorrhizal growth and uptake responses were calculated as suggested by [36].

\subsection{Statistical Analysis}

The statistical analysis was done after data were checked for normality and variance homogeneity using Shapiro-Wilk and Levene's tests from R software [37]. Multiple analysis of variance (MANOVA) procedure was performed to test the main factor effects and their interactions on the different measured parameters. Percentage data for the MCF and MCI were square root-arcsin transformed before the ANOVA analyses. The boxplots of the dataset distribution range represent the IQR (interquartile range), median, and means for the measured parameters are presented.

\section{Results}

\subsection{Chemical Properties of the Used Soils}

The chemical properties analyzed for the composite soils were organic carbon (\%), $1.15 \pm 0.14$; nitrogen content $(\%), 0.02 \pm 0.01$; electric conductivity $(\mathrm{mS} / \mathrm{cm}), 0.86 \pm 0.03$; $\mathrm{pH}\left(\mathrm{H}_{2} \mathrm{O}\right), 8.8 \pm 0.02$; limestone content $(\%), 22.4 \pm 4.01$, and available phosphorus content $\left(\mathrm{mg} \mathrm{P} \mathrm{kg}^{-1}\right), 8.1 \pm 2.01$. 


\subsection{Variance Analysis}

Mycorrhiza colonization intensity, the root-to-shoot ratio, $\mathrm{P}$ and $\mathrm{N}$ uptakes, PUE in the shoots, and P uptake in the roots were significantly different for the tested legume species (Table 1). All the measured parameters for the two legume species, except the root-to-shoot ratio, showed a significant difference under the salt (S) treatments (Table 1). Among the tested interactions, the legume (L) species $\times \mathrm{S}$ interaction was significant at $p<0.05$ for the shoot and root DMs, P uptake, and PUE in the shoot and roots. The shoot $\mathrm{N}$ uptake also showed a significant $\mathrm{L} \times \mathrm{S}$ interaction (Table 1). The $\mathrm{L} \times \mathrm{M}$ and $\mathrm{L} \times \mathrm{M}$ interactions were significant for the mycorrhizal colonization intensity (Table 1). We further observed a significant $\mathrm{L} \times \mathrm{M}$ interaction for the mycorrhiza colonization frequency, $\mathrm{P}$ and $\mathrm{N}$ uptakes in the shoots, and PUE in the root (Table 1). The triple interaction $(\mathrm{L} \times \mathrm{S} \times \mathrm{M})$ effect was significant for the P uptake in the shoots, and $\mathrm{N}$ uptake in the roots (Table 1).

Table 1. Results of 2- and 3-way analysis of variance testing the effects of legume species (L) (2 levels: Acacia gummifera and Retama monosperma), mycorrhizal (M) inoculation (absence or presence of AMF) and salt (S) treatments (0-, 25-, 50- and $100 \mathrm{mM} \mathrm{L}^{-1} \mathrm{NaCl}$ concentrations), and interactions on the measured plants' parameters at 180 days after transplanting.

\begin{tabular}{|c|c|c|c|c|c|c|c|c|c|c|c|c|}
\hline \multirow{2}{*}{$\begin{array}{l}\text { Source of } \\
\text { Variation }\end{array}$} & \multicolumn{12}{|c|}{ F Value } \\
\hline & DF & MCF & MCI & SDM & RDM & R-S & SPU & RPU & PUE $_{\text {shoot }}$ & PUE & SNU & RNU \\
\hline $\begin{array}{l}\text { Legume (L) } \\
\text { species }\end{array}$ & 1 & $1.4(\mathrm{~ns})$ & $10.7(* *)$ & 1.5 (ns) & 2.9 (ns) & $6.5\left(^{*}\right)$ & 0.7 (ns) & $\begin{array}{l}32.5 \\
(* * *)\end{array}$ & $3.8\left(^{*}\right)$ & $6.4\left(^{*}\right)$ & $\left.12.9^{* *}\right)$ & $\begin{array}{l}0.05 \\
\text { (ns) }\end{array}$ \\
\hline $\begin{array}{l}\text { Salinity }(\mathrm{S}) \\
\text { treatment }\end{array}$ & 3 & $\begin{array}{l}46.6 \\
(* * *)\end{array}$ & $\begin{array}{l}109.7 \\
(* * *)\end{array}$ & $5.7\left(^{* *}\right)$ & $\begin{array}{l}11.7 \\
(* * *)\end{array}$ & 0.5 (ns) & $\begin{array}{l}30.1 \\
(* * *)\end{array}$ & $\begin{array}{l}71.8 \\
(* * *)\end{array}$ & $\begin{array}{l}37.6 \\
(* * *)\end{array}$ & $\begin{array}{l}25.7 \\
(* * *)\end{array}$ & $7.9\left(^{* * *}\right)$ & $\begin{array}{l}20.3 \\
(* * *)\end{array}$ \\
\hline $\begin{array}{l}\text { Mycorrhizal } \\
\text { (M) inoculation }\end{array}$ & 1 & $\begin{array}{l}463.0 \\
(* * *)\end{array}$ & $\begin{array}{c}582.0 \\
(* * *)\end{array}$ & $\begin{array}{l}37.8 \\
(* * *)\end{array}$ & $\begin{array}{l}70.4 \\
(* * *)\end{array}$ & $\begin{array}{l}0.01 \\
\text { (ns) }\end{array}$ & $\begin{array}{l}20.0 \\
(* * *)\end{array}$ & $\begin{array}{c}111.7 \\
(* * *)\end{array}$ & 0.4 (ns) & $\begin{array}{l}20.6 \\
(* * *)\end{array}$ & $\begin{array}{l}67.3 \\
(* * *)\end{array}$ & $\begin{array}{l}68.7 \\
(* * *)\end{array}$ \\
\hline $\mathrm{L} \times \mathrm{S}$ & 3 & 0.5 (ns) & 0.7 (ns) & $4.1\left(^{*}\right)$ & $3.9\left(^{*}\right)$ & $2.3(\mathrm{~ns})$ & $\begin{array}{l}10.6 \\
(* * *)\end{array}$ & $\begin{array}{l}10.4 \\
(* * *)\end{array}$ & $\left.7.6{ }^{(* * *}\right)$ & $\begin{array}{l}16.6 \\
(* * *)\end{array}$ & $8.5\left(^{* * *}\right)$ & 2.4 (ns) \\
\hline $\mathrm{L} \times \mathrm{M}$ & 1 & 1.4 (ns) & $10.7\left(^{* *}\right)$ & 0.1 (ns) & 0.8 (ns) & 0.3 (ns) & 0.6 (ns) & 0.2 (ns) & $\begin{array}{l}0.01 \\
\text { (ns) }\end{array}$ & $\begin{array}{l}0.01 \\
\text { (ns) }\end{array}$ & 1.9 (ns) & 0.5 (ns) \\
\hline $\mathrm{S} \times \mathrm{M}$ & 3 & $\begin{array}{l}43.6 \\
(* * *)\end{array}$ & $\begin{array}{l}109.7 \\
(* * *)\end{array}$ & 0.1 (ns) & $1.8(\mathrm{~ns})$ & 1.1 (ns) & $3.3\left(^{*}\right)$ & 1.5 (ns) & 0.7 (ns) & $\left.5.1{ }^{* *}\right)$ & $6.5\left(^{* * *}\right)$ & 0.6 (ns) \\
\hline $\mathrm{L} \times \mathrm{S} \times \mathrm{M}$ & 3 & $0.5(\mathrm{~ns})$ & $0.5(\mathrm{~ns})$ & 0.9 (ns) & 0.7 (ns) & 1.1 (ns) & $3.0\left(^{*}\right)$ & $5.0(* *)$ & 0.6 (ns) & 0.4 (ns) & $2.3(\mathrm{~ns})$ & $\left.5.4{ }^{* *}\right)$ \\
\hline $\begin{array}{l}\text { Coefficient of } \\
\text { variation }(\%)\end{array}$ & & 10.2 & 9.0 & 17.2 & 12.8 & 17.3 & 32.0 & 18.5 & 20.7 & 33.0 & 15.0 & 20.7 \\
\hline
\end{tabular}

Mycorrhizal colonization frequency (MCF); mycorrhizal colonization intensity (MCI); shoot dry mass (SDM); root dry mass (RDM); root-shoot ratio (R-S); shoot-P uptake (SPU); root-P uptake (RPU); P use efficiency in shoots (PUE $\mathrm{shot}_{\text {sho }}$; $\mathrm{P}$ use efficiency in root (PUE root); shoot-N uptake (SNU); root-N uptake (RNU); numbers followed by ${ }^{*},{ }^{* *}$, and ${ }^{* * *}$ were significant at $p<0.05, p<0.01$, and $p<0.001$ by $t$-test, respectively.

\subsection{Mycorrhizal Root Colonization Frequencies and Intensities}

Only values of the mycorrhizal root colonization frequencies and intensities of the inoculated treatments are presented, as the no-inoculated treatments had no colonization due to the sterile conditions of the soil (Figure 1a,b). Mycorrhizal root colonization frequencies and intensities were inhibited by the $\mathrm{S}$ treatments with plants under 50 - and $100-\mathrm{mM} \mathrm{L}^{-1}$ $\mathrm{NaCl}$ treatments highly damaged (Figure 1a,b). Mycorrhizal root colonization intensity was consistently lower under A. gummifera than R. monosperma species at the different salt concentrations used (Figure 1b).

\subsection{Shoot and Root Dry Matter (DM)}

The boxplots of the shoot and root DMs and root-to-shoot ratio of the non-inoculated and inoculated-treated plants of A. gummifera and R. monosperma species exposed to different salt concentrations are presented in Figure $2 \mathrm{a}-\mathrm{c}$. Shoot and root DMs were inhibited by the $\mathrm{S}$ stress, and the salt-treated plants showed lower DMs compared to no-salt ones for A. gummifera (Figure 2a,b). For R. monosperma, shoot and root DMs were also reduced significantly under the 25 and $100 \mathrm{mM} \mathrm{L}^{-1}$ only, compared to the no-salt treatment. 


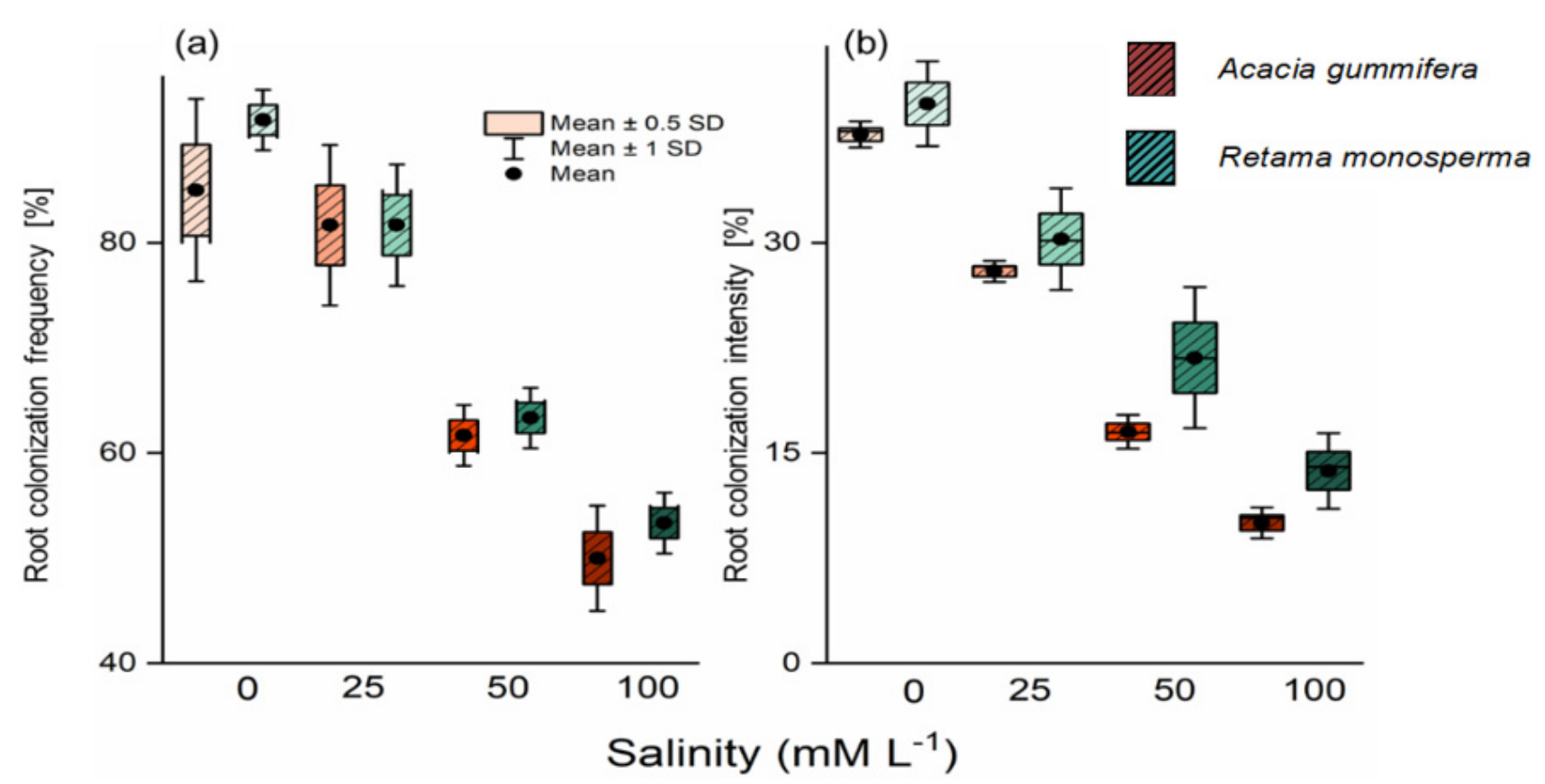

Figure 1. Boxplots of mycorrhizal frequency (a) and intensity (b) of the inoculated Acacia gummifera and Retama monosperma plants under different salinity levels $(0,25,50$ and $100 \mathrm{mM} \mathrm{NaCl})$. At the different salinity concentration, A. gummifera species are represented by antiwhite and brown colors, and R. monosperma species are shown by tea-green, and green colors, respectively.

(a)
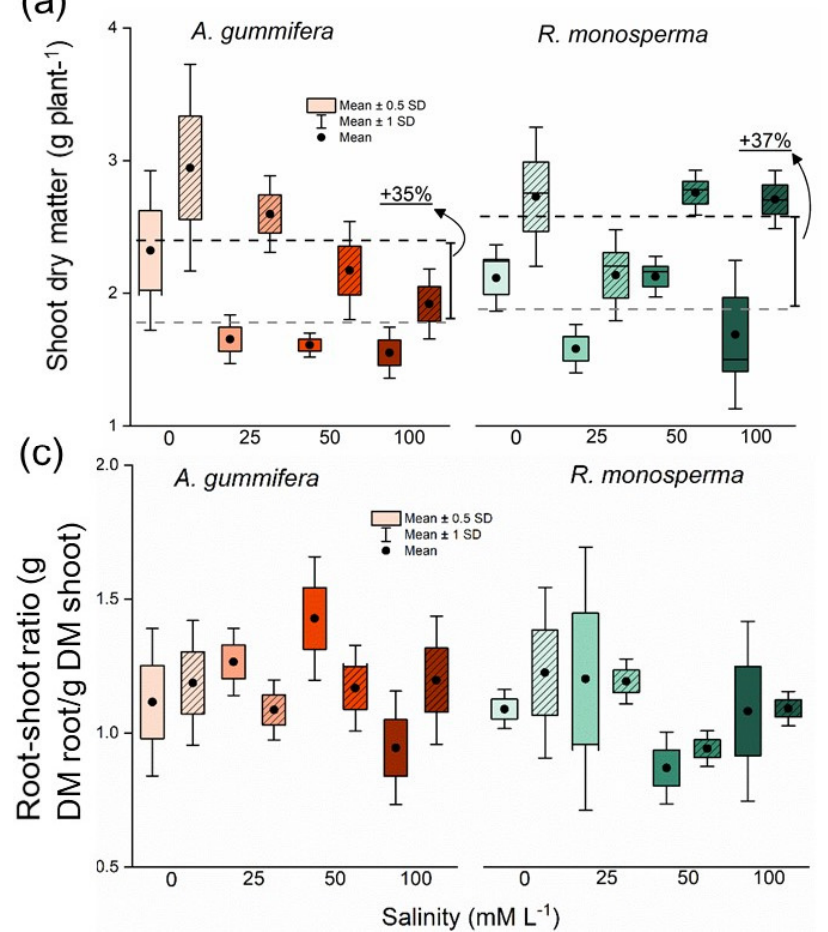

(b) ${ }^{4}$ R. monosperma

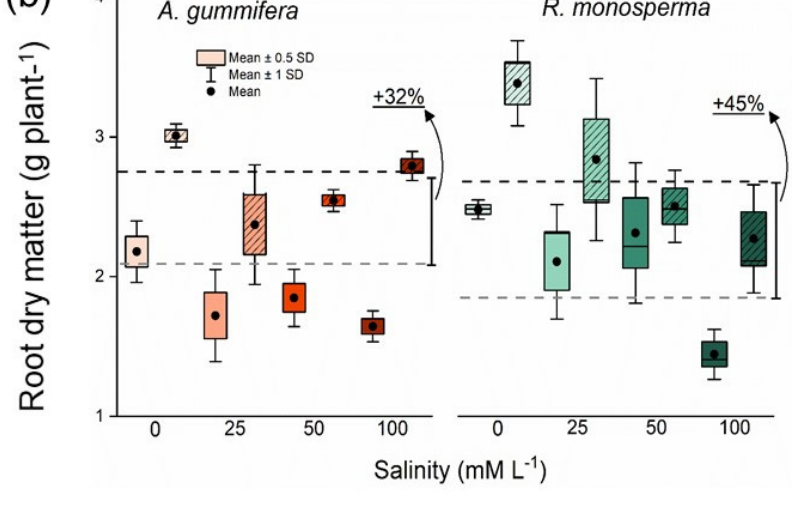

Acacia gummifera

Retama monosperma

Figure 2. Boxplots of shoot (a), root (b) dry matter, and root-to shoot ratio (c) of the non-inoculated and inoculated Acacia gummifera and Retama monosperma plants under different salinity levels $(0,25,50$ and $100 \mathrm{mM} \mathrm{NaCl})$. The average values of the mycorrhizal shoot and root growth responses for A. gummifera and $R$. monosperma species are shown by the percentage of increased value. Mycorrhizal inoculated plants are represented by dashed boxplots for both A. gummifera and R. monosperm a species. At the different salinity concentration, A. gummifera species are represented by antiwhite and brown colors, and $R$. monosperma species are shown by tea-green, and green colors, respectively. 
As shown in Figure 2a,b, unexpectedly, there was no significant difference between the $50 \mathrm{mM} \mathrm{L}^{-1}$ and the no-salt salt treatments about the shoot and root DMs (Figure 2a,b). Shoot and root DMs were always higher in the mycorrhiza inoculated than in the noninoculated treatments under the $0,25,50$, and $100 \mathrm{mM} \mathrm{L}^{-1}$ of $\mathrm{NaCl}$ treatment, respectively (Figure 2a,b). The average value of mycorrhizal shoot and root growth response was by $35 \%$, and $37 \%$ in the A. gummifera and R. monosperma plants about the shoot DM, respectively (Figure 2a). Similarly, the average value of mycorrhizal shoot and root growth response were $32 \%$ and $45 \%$ in the $A$. gummifera and $R$. monosperma species, respectively (Figure 2b). The root-to-shoot ratio significantly differed between the two legume species with no observed difference due to the $\mathrm{M}$ inoculation and imposed $\mathrm{S}$ treatments (Figure 2c). The root-to-shoot ratio values ranged from 0.8 to 1.7 , and the mycorrhizal inoculated A. gummifera plants under the $100 \mathrm{mM} \mathrm{L}^{-1} \mathrm{NaCl}$ treatment displayed the lowest value, while the non-inoculated treatment under $50 \mathrm{mM} \mathrm{L}^{-1}$ of $\mathrm{NaCl}$ treatment for the same species showed the highest value (Figure 2c).

\subsection{Tissue-P Concentration and PUE}

Tissue-P concentration was calculated by multiplying the P concentration by the dry weight of shoot, and roots of mycorrhizal inoculated plants was higher than in the noninoculated under the different $S$ treatments, whereas there was no significant difference in shoot P uptake between the two legume species (Figure 3a,b). The salt stress highly inhibited the P uptake in the shoots and the roots for both legume species (Figure 3a,b). The average value of mycorrhizal shoot and root $P$ uptake responses were $66 \%$ and $68 \%$ for A. gummifera plants (Figure 3a,b). For the R. monosperma species, the average values of mycorrhizal shoot and root $\mathrm{P}$ uptake response were $40 \%$ and $95 \%$ higher in the inoculated than in the non-inoculated plants (Figure 3a,b).

The PUE in the shoots and the roots was significantly different for the two legume species (Figure $4 a, b$ ). Phosphorus utilization in the shoots and the roots was lower in the nosalt than in the salt-treated plants for both legumes (Figure 4a,b). Mycorrhizal inoculated plants maintained a lower PUE in the roots under the different $S$ treatments, whereas the $\mathrm{M}$ effect was less pronounced in the shoots for the A. gummifera and R. monosperma plants (Figure 4a,b).

\subsection{Nitrogen Uptake in the Shoots and the Roots}

Nitrogen uptake in the shoots and the roots of A. gummifera and R. monosperma trees are presented in Figure 5a,b. The two legume species had highly different $\mathrm{N}$ uptake values in the shoots, but not the roots (Figure 5a,b). The salt stress inhibited the $\mathrm{N}$ uptake in the shoots and the roots, and the highest inhibition effects were observed under the 50 and $100 \mathrm{mM} \mathrm{L}^{-1}$ treatments for the $\mathrm{N}$ uptake in the roots of A. gummifera and $R$. monosperma species (Figure 5a,b). Mycorrhizal inoculation increased the $\mathrm{N}$ uptake in the shoots and the roots under the different $S$ treatments. Nitrogen uptake in the shoots and the roots was higher in the inoculated than in the non-inoculated treatments under the different salt concentrations, except the $50 \mathrm{mM} \mathrm{L}^{-1}$ about $\mathrm{N}$ uptake in the shoots for A. gummifera species (Figure 5a,b). The average values of mycorrhizal shoot and root $\mathrm{M}$ uptake response were $75 \%$ and $59 \%$ higher in the inoculated than in the non-inoculated A. gummifera species (Figure 3a,b). Similarly, the average value of mycorrhizal M uptake response was 74.1\%, and $74 \%$ in the shoots and the roots, respectively, for $R$. monosperma species (Figure 5a,b). 
(a)

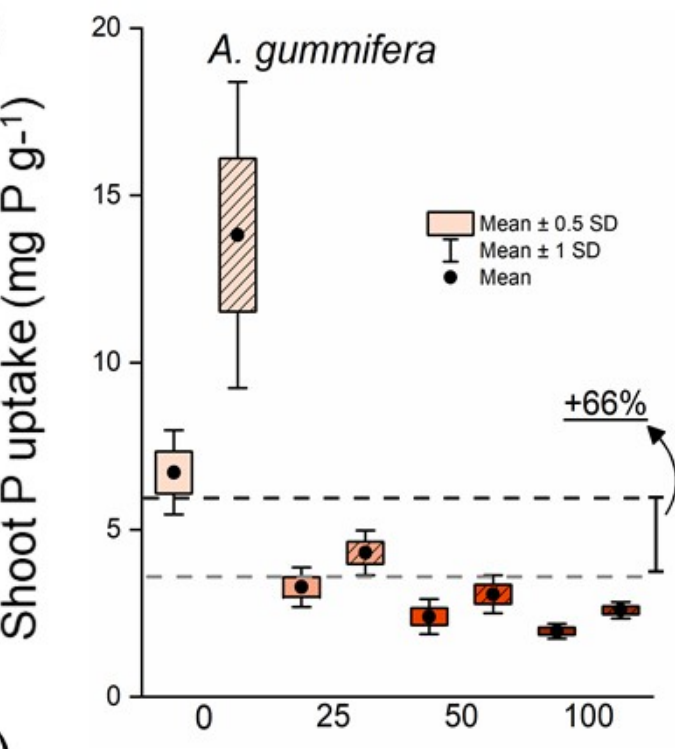

(b)

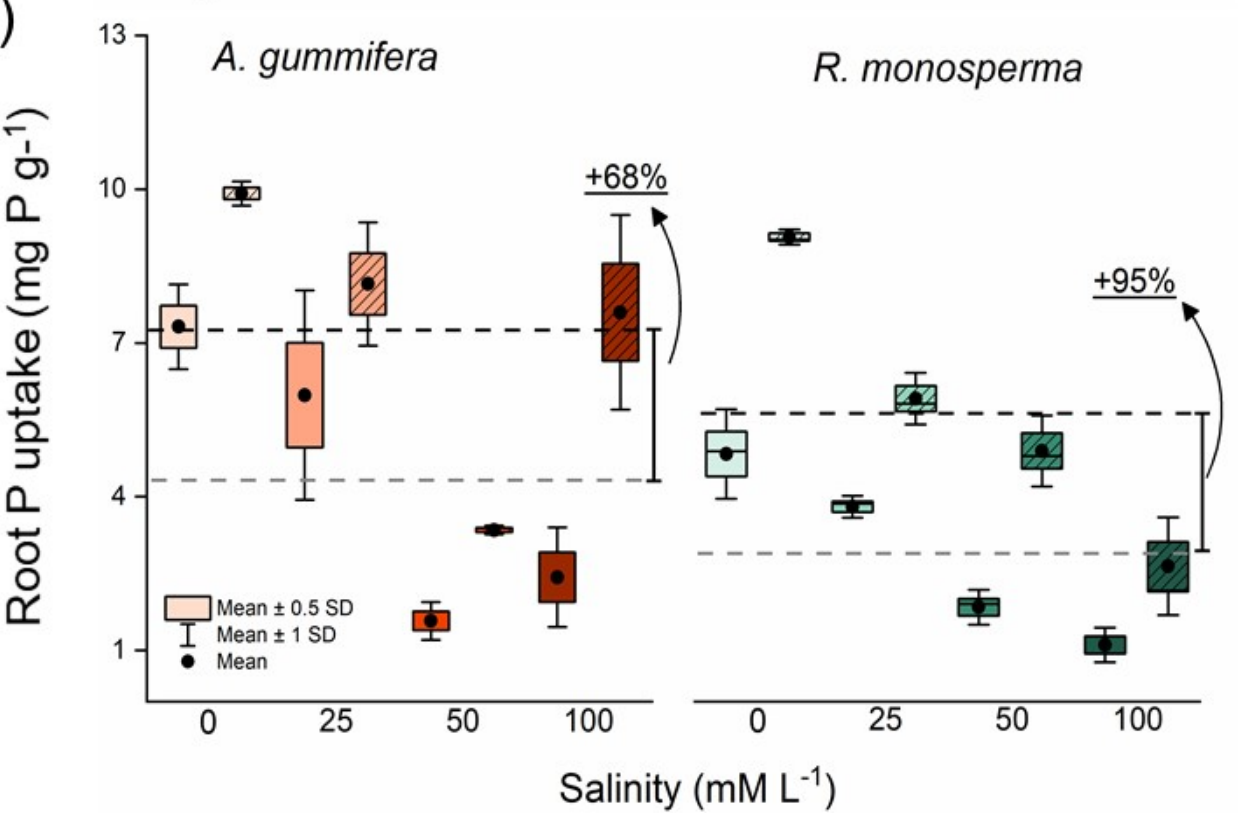

Figure 3. Boxplots of P uptake in the shoot (a) and root (b) of the non-inoculated and inoculated Acacia gummifera and Retama monosperma plants under different salinity levels $(0,25,50$ and $100 \mathrm{mM}$ $\mathrm{NaCl}$ ). The average values of mycorrhizal shoot and root $\mathrm{P}$ uptake response for A. gummifera and R. monosperma species are shown by the percentage of increased response. Mycorrhizal inoculated plants are represented by dashed boxplots for both $A$. gummifera and $R$. monosperms species. At the different salinity concentration, A. gummifera species are represented by antiwhite and brown colors, and R. monosperma species are shown by tea-green, and green colors, respectively. 


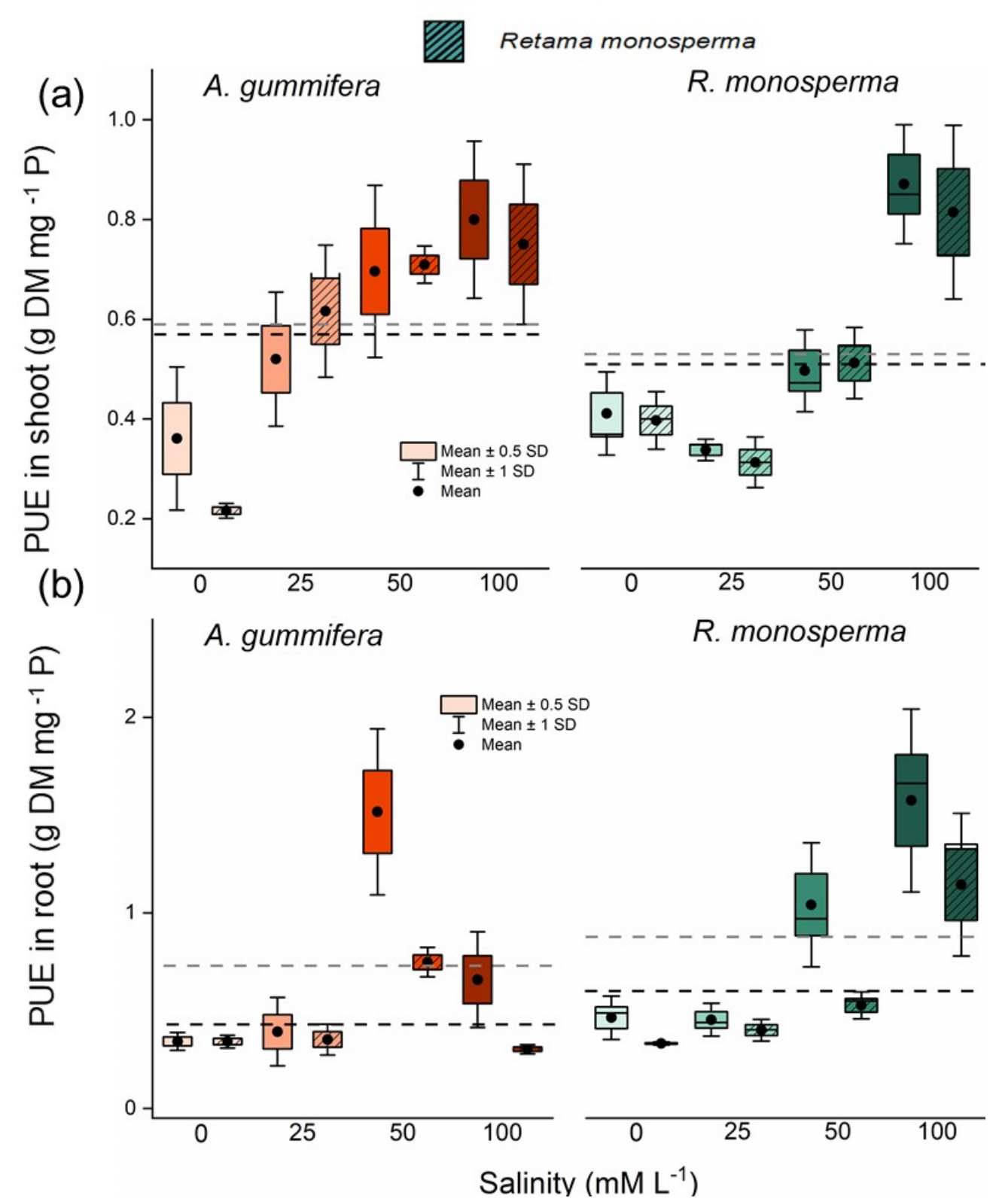

Figure 4. Boxplots of P utilization efficiency (PUE) in the shoot (a) and root (b) of the non-inoculated and inoculated (a) Acacia gummifera and (b) Retama monosperma plants grown under different salinity levels $(0,25,50$ and $100 \mathrm{mM} \mathrm{NaCl})$. Mycorrhizal inoculated plants are represented by dashed boxplots. Mycorrhizal inoculated plants are represented by dashed boxplots for both A. gummifera and R. monosperma species. At the different salinity concentration, A. gummifera species are represented by antiwhite and brown colors, and R. monosperma species are shown by tea-green, and green colors, respectively. 


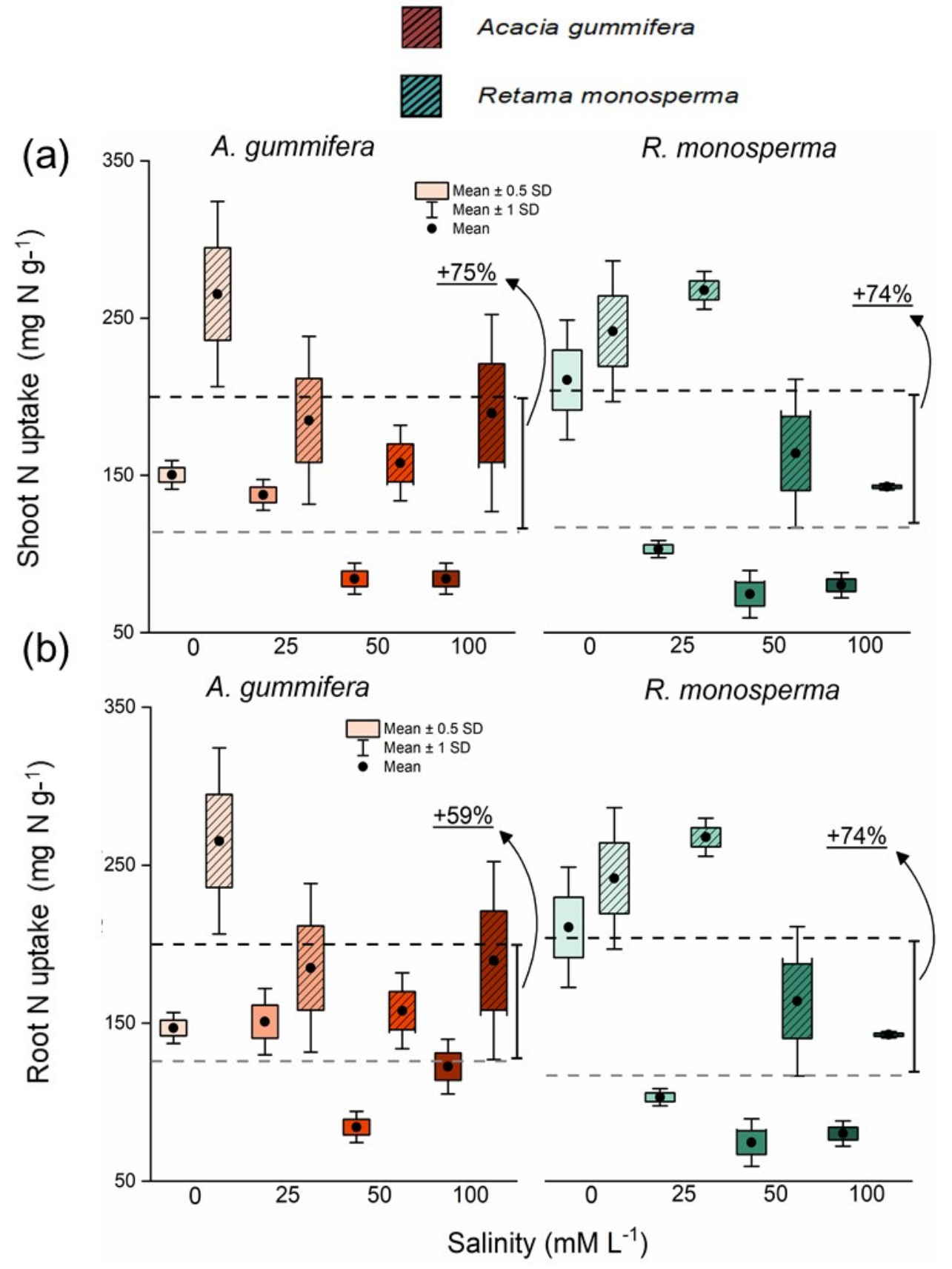

Figure 5. Boxplots of $\mathrm{N}$ uptake in the shoot (a) and in the root (b) of the non-inoculated and mycorrhizal inoculated Acacia gummifera and Retama monosperma plants grown under different salinity levels $(0,25,50$ and $100 \mathrm{mM} \mathrm{NaCl})$. The average values of mycorrhizal shoot and $\operatorname{root} \mathrm{N}$ uptake response for A. gummifera and R. monosperma species are shown by the percentage of increased value. Mycorrhizal inoculated plants are represented by dashed boxplots for both A. gummifera and R. monosperms species. At the different salinity concentration, A. gummifera species are represented by antiwhite and brown colors, and R. monosperma species are shown by tea-green, and green colors, respectively.

\section{Discussion}

Salinity stress is rapidly increasing by an estimated $0.3-1.5$ million ha ${ }^{-1}$ of farmland yearly, thereby decreasing crop productivity by more than $20 \%$ [8]. Deposition from seawater, poor water drainage facilities, and improper irrigation practices from underground are the primary causes of high salinity encountered in the Atlantic forest coast of Morocco [38]. The present study was conducted to explore interventions that exploit the soil ecological 
processes and functions conferred by beneficial soil microbes such as PGPRs and AMF to promote rapid reforestation/afforestation programs of the Atlantic Coastal forest of the Essaouira region. The results from the present study showed a salt inhibitory effect on the mycorrhizal root colonization frequencies and intensities (Figure 1a,b). The tested legume species showed different tolerance responses to salt stress in relation to the intensity of mycorrhizal root colonization (Figure 1b). The inhibitory effect of salt stress on the intensity of mycorrhizal root colonization of $R$. monosperma was lower than A. gummifera plants. Previous studies investigating salinity effects on the mycorrhizal root colonization intensity also showed salt detrimental effects on spore germination, hyphal growth, and root colonization rate and intensity of plants [39,40]. A decrease in root colonization of Gi. margarita and G. etunicatum with increasing levels of salinity $\left(100 \mathrm{mM} \mathrm{L}^{-1} \mathrm{NaCl}\right)$ was also reported (Yang et al. 2020). The mycorrhizal inhibition effect under high salinity concentrations are caused by high $\mathrm{NaCl}$ concentration that represses hyphal growth, spore germination, and inhibits the root colonization intensity of inoculated plants [41].

The growth and development of all tested legume species were reduced by salt stress. A. gummifera was more susceptible to high salinity level than $R$. monosperma. Inoculation with mycorrhizal aided the used species to mitigate damages from salt stress on dry biomass production (Figure 2a,b). Furthermore, the average values of mycorrhizal shoot and root growth responses were higher in the R. monosperma than in the A. gummifera plants (Figure 2a,b). In various plants including lettuce (Lactuca sativa), sorghum, and olive (Olea europaea) trees, the benefit of AMF inoculation to mitigate salt stress were previously reported $[9,18,42]$. On lettuce plants, the use of Glomus species increased root and shoot dry weights than in the non-mycorrhizal inoculated plants due to an enhancement of proline accumulation from host plants under salt conditions [9]. On sorghum, mycorrhizal inoculation with Acaulospora mellea species improved the plant's biomass production by enhancing superoxide dismutase, peroxidase, and catalase activities, and increase of soluble sugar uptake in the leaves of the inoculated than in the non-inoculated plants under high $\mathrm{NaCl}$ supply [18]. Although we lack comparable data for A. gummifera and R. monosperma trees under saline soil conditions of Morocco, shoot and root growth increases of $239 \%$ and $468 \%$ were seen using locally isolated Glomus mosseae, G. intraradices or G. claroideum species on olive trees [42]. The mycorrhizal growth enhancement was attributed to the ability of inoculated plants to boost the N, P, and K uptakes under high salt conditions and their translocation into the shoots and leaves [42].

In the present study, P uptake in the shoot and roots was reduced by salt stress. Phosphorus availability to plants under saline conditions is proven to greatly decrease around the root zones due to $\mathrm{P}$ ions precipitation, concomitantly with $\mathrm{Ca}^{2+}, \mathrm{Mg}^{2+}$, and $\mathrm{Zn}^{2+}$ ions [8]. The reduction in P uptake under saline soil conditions was reported by [42]. The fact that the two species expressed different tolerance response to salt regarding $\mathrm{P}$ uptake in the roots could be exploited in the selection of choice of plant targeting the reforestation program with better root adaptation to salt and increased uptake efficiency.

Phosphorus utilization in the shoots and roots was strongly affected by salt stress treatments and the lowest PUE values were in the $0 \mathrm{mM}$ compared to the 25,50 and $100 \mathrm{mM} \mathrm{L}^{-1}$ of $\mathrm{NaCl}$ treatments for both legume species (Figure $4 \mathrm{a}, \mathrm{b}$ ). Mycorrhizal inoculation maintained a lower PUE in the roots than in the shoots. Plants exposed to high salinity often suffer from osmotic stress, which leads to nutritional disorders and inhibition of plant growth. The results are consistent with previous studies that showed the negative impact of salt stress on the PUE in the roots [27]. To evaluate the combined effects of phosphorus deficiency and salt tolerance in maize plants, [27] it was also observed that salinity predominantly affected root growth and reduced plant $\mathrm{P}$ uptake. The adverse impact of salt stress on PUE in the roots could be due to possible root adjustment strategies that enable plants to increase their P uptake and reduce their translocations into the shoot parts. Mycorrhiza enabled the plants to increase P uptake and favored root expansion as a mechanism to build salt stress tolerance. We lack comparable data investigating the PUE of the two test species under salt stress. The results call for further investigations to elucidate 
the mechanism by which AMF alters PUE under salt stress. Other possible roles of AMF to alter the PUE of host plants could be due to the increase of hyphae extension out of the rhizosphere, accessing $\mathrm{P}$ to facilitate their translocation to mimic the salt stress [15]. Other possible mechanisms may involve the overexpression of genes involved in $\mathrm{Na}^{+}$extrusion to the soil solution, favoring better $\mathrm{K}^{+}$acquisition to maintain favorable $\mathrm{Na}^{+}: \mathrm{K}^{+}$ratio under salt stress [16-18].

In the present investigation, $\mathrm{N}$ accumulation in the shoots and the roots decreased due to the imposed salt stress, and mycorrhizal inoculation significantly reduced salt damaging effects on the shoot and root $\mathrm{N}$ accumulation of both tested species (Figure $5 \mathrm{a}, \mathrm{b}$ ). Salinity hinders $\mathrm{N}$ assimilation by perturbing $\mathrm{NO}_{3}{ }^{-}$assimilation and impairing protein synthesis [43]. In rice plants, $\mathrm{N}$ accumulation in the shoots and the roots was also reduced due to imposed salt stress [43]. Mycorrhizal fungal's role is in supporting plants to assimilate $\mathrm{N}$ under various stress conditions via the hyphae that obtain nitrate from the soil and transform it using nitrate reductase; this is an emerging area of the fungal studies [44]. Recent work showed that plant root's associations with AMF reduce not only the number of plant nutrients leached from the soil but also the amount of $\mathrm{N}_{2} \mathrm{O}$ emitted from the soil through denitrification [21,45]. Given that $\mathrm{N}$ is a severely limiting nutrient in dunes, the roles of mycorrhizal could be pivotal in the transformation of non-available forms of $\mathrm{N}$ to forms that can be assimilated by R. monosperma and A. gummifera for a rapid afforestation program in the region.

\section{Conclusions}

The present investigation evaluated the growth and phosphorus uptake responses of two legume species to salt stress and the effectiveness of mycorrhizal to mitigate the salt stress. The two test legume species differed in the pattern of the mycorrhizal colonization frequency and intensity levels, root-to-shoot ratio, N and P tissue concentrations, PUE in the shoot, and the roots under different $S$ treatments. Salt stress inhibited most of the measured legumes' growth and uptake parameters. Mycorrhizal inoculation helped the two legume species to mitigate the effects of salt stress, with better P uptake response found in the roots than in the shoots at high salt concentration. The adverse impacts of salt stress on PUE efficiency in roots was more pronounced for A. gummifera than in the $R$. monosperma under high salinity concentration, and the two species expressed different tolerance responses to salt regarding PUE in roots. Recognizing that the PUE of plants is a very complex plant trait, future research targeting PUE improvements under salt stress will be investigated in the frame of the present project. The PUE in the roots of mycorrhizal inoculated treatments was always lower than in the non-inoculated treatments, indicating the role of AMF in the alteration of the PUE. The result calls for future investigations of physiological, biochemical, and molecular mechanisms for tolerance response to salinity stress by A. gummifera and R. monosperma conferred by the AMF for a sustainable and ecological management of the forest in the Atlantic coast regions.

Author Contributions: For research articles with several authors, the following statements should be used "Conceptualization, A.F., L.O. and M.H.; methodology, A.F., L.O., M.H.; software, M.J., M.H.; validation, A.F., M.H. and M.J.; formal analysis, A.F.; investigation, M.H., L.O.; resources, A.F. and M.J.; data curation, A.F. and M.J.; writing-original draft preparation, A.F., M.H., N.M., and M.J. writing—review and editing, A.F., M.H., N.M., L.O., and M.J.; supervision, M.H.; L.O.; project administration, M.H.; funding acquisition, M.H. All authors have read and agreed to the published version of the manuscript."

Funding: This work was financially supported by a grant from the Laboratory of Microbial Biotechnologies, Agrosciences and Environment Faculty of Science Semlalia, Marrakesh, Morocco.

Data Availability Statement: Not applicable. 
Acknowledgments: This work was financially supported by a grant from the Laboratory of Microbial Biotechnologies, Agrosciences and Environment Faculty of Science Semlalia, Marrakesh, Morocco. The authors would also like to extend their sincere appreciation to the Centre Régional de la Recherche Forestière (CRRF) of Marrakesh for the supply of A. gummifera and R. monosperma seeds.

Conflicts of Interest: The authors declare no conflict of interest

\section{References}

1. Fakhech, A.; Manaut, N.; Ouahmane, L.; Hafidi, M. Contributions of Indigenous Arbuscular Mycorrhizal Fungi to Growth of Retama Monosperma and Acacia Gummifera under Water Stress (Case Study: Essaouira Sand Dunes Forest). J. Sustain. For. 2019, 38, 686-696. [CrossRef]

2. Kearl, J.; McNary, C.; Lowman, J.S.; Mei, C.; Aanderud, Z.T.; Smith, S.T.; West, J.; Colton, E.; Hamson, M.; Nielsen, B.L. SaltTolerant Halophyte Rhizosphere Bacteria Stimulate Growth of Alfalfa in Salty Soil. Front. Microbiol. 2019, 10, 1849. [CrossRef] [PubMed]

3. Evelin, H.; Kapoor, R.; Giri, B. Arbuscular Mycorrhizal Fungi in Alleviation of Salt Stress: A Review. Ann. Bot. 2009, 104, 1263-1280. [CrossRef] [PubMed]

4. Yang, Y.; Guo, Y. Unraveling Salt Stress Signaling in Plants: Salt Stress Signaling. J. Integr. Plant Biol. 2018, 60, 796-804. [CrossRef]

5. Arzani, A.; Ashraf, M. Smart Engineering of Genetic Resources for Enhanced Salinity Tolerance in Crop Plants. Crit. Rev. Plant Sci. 2016, 35, 146-189. [CrossRef]

6. Yu, Z.; Duan, X.; Luo, L.; Dai, S.; Ding, Z.; Xia, G. How Plant Hormones Mediate Salt Stress Responses. Trends Plant Sci. 2020, 11, P1117-P1130. [CrossRef]

7. Orozco-Mosqueda, M.d.C.; Duan, J.; DiBernardo, M.; Zetter, E.; Campos-García, J.; Glick, B.R.; Santoyo, G. The Production of ACC Deaminase and Trehalose by the Plant Growth Promoting Bacterium Pseudomonas Sp. UW4 Synergistically Protect Tomato Plants Against Salt Stress. Front. Microbiol. 2019, 10, 1392. [CrossRef]

8. Evelin, H.; Devi, T.S.; Gupta, S.; Kapoor, R. Mitigation of Salinity Stress in Plants by Arbuscular Mycorrhizal Symbiosis: Current Understanding and New Challenges. Front. Plant Sci. 2019, 10, 470. [CrossRef] [PubMed]

9. Ruiz-Lozano, J.M.; Azcon, R.; Gomez, M. Alleviation of Salt Stress by Arbuscular-Mycorrhizal Glomus Species in Lactuca Sativa Plants. Physiol. Plant. 1996, 98, 767-772. [CrossRef]

10. James, D.; Borphukan, B.; Fartyal, D.; Ram, B.; Singh, J.; Manna, M.; Sheri, V.; Panditi, V.; Yadav, R.; Achary, V.M.M.; et al. Concurrent Overexpression of OsGS1;1 and OsGS2 Genes in Transgenic Rice (Oryza Sativa L.): Impact on Tolerance to Abiotic Stresses. Front. Plant Sci. 2018, 9, 786. [CrossRef]

11. Isayenkov, S.V.; Maathuis, F.J.M. Plant Salinity Stress: Many Unanswered Questions Remain. Front. Plant Sci. 2019, 10, 80. [CrossRef]

12. Kumar, J.; Singh, S.; Singh, M.; Srivastava, P.K.; Mishra, R.K.; Singh, V.P.; Prasad, S.M. Transcriptional Regulation of Salinity Stress in Plants: A Short Review. Plant Gene 2017, 11, 160-169. [CrossRef]

13. Saddhe, A.A.; Malvankar, M.R.; Karle, S.B.; Kumar, K. Reactive Nitrogen Species: Paradigms of Cellular Signaling and Regulation of Salt Stress in Plants. Environ. Exp. Bot. 2019, 161, 86-97. [CrossRef]

14. Augé, R.M.; Toler, H.D.; Saxton, A.M. Arbuscular Mycorrhizal Symbiosis Alters Stomatal Conductance of Host Plants More under Drought than under Amply Watered Conditions: A Meta-Analysis. Mycorrhiza 2015, 25, 13-24. [CrossRef]

15. Smith, S.; Read, D. Mycorrhizal Symbiosis, 3rd ed.; Academic Press: London, UK, 2008.

16. Bothe, H. Arbuscular Mycorrhiza and Salt Tolerance of Plants. Symbiosis 2012, 58, 7-16. [CrossRef]

17. Porcel, R.; Aroca, R.; Azcon, R.; Ruiz-Lozano, J.M. Regulation of Cation Transporter Genes by the Arbuscular Mycorrhizal Symbiosis in Rice Plants Subjected to Salinity Suggests Improved Salt Tolerance Due to Reduced Na+ Root-to-Shoot Distribution. Mycorrhiza 2016, 26, 673-684. [CrossRef] [PubMed]

18. Wang, F.; Sun, Y.; Shi, Z. Arbuscular Mycorrhiza Enhances Biomass Production and Salt Tolerance of Sweet Sorghum. Microorganisms 2019, 7, 289. [CrossRef]

19. Ren, C.-G.; Kong, C.-C.; Xie, Z.-H. Role of Abscisic Acid in Strigolactone-Induced Salt Stress Tolerance in Arbuscular Mycorrhizal Sesbania Cannabina Seedlings. BMC Plant Biol. 2018, 18, 74. [CrossRef] [PubMed]

20. Chen, Y.L.; Liu, R.J.; Bi, Y.L.; Feng, G. Use of Mycorrhizal Fungi for Forest Plantations and Minesite Rehabilitation. In Mycorrhizal Fungi: Use in Sustainable Agriculture and Land Restoration; Solaiman, Z.M., Abbott, L.K., Varma, A., Eds.; Soil Biology; Springer: Berlin/Heidelberg, Germany, 2014; pp. 325-355. ISBN 978-3-662-45370-4.

21. Bender, S.F.; Wagg, C.; van der Heijden, M.G.A. An Underground Revolution: Biodiversity and Soil Ecological Engineering for Agricultural Sustainability. Trends Ecol. Evol. 2016, 31, 440-452. [CrossRef]

22. Fakhech, A.; Ouahmane, L.; Hafidi, M. Analysis of Symbiotic Microbial Status of Atlantic Sand Dunes Forest and Its Effects on Acacia Gummifera and Retama Monosperma (Fabaceae) to Be Used in Reforestation. J. For. Res. 2020, 31, 1309-1317. [CrossRef]

23. Lamin, H.; Alami, S.; Bouhnik, O.; ElFaik, S.; Abdelmoumen, H.; Bedmar, E.J.; Missbah-El Idrissi, M. Nodulation of Retama Monosperma by Ensifer Aridi in an Abandonned Lead Mine Soils in Eastern Morocco. Front. Microbiol. 2019, 10, 1456. [CrossRef]

24. Tak, N.; Gehlot, H.S. Diversity of Nitrogen-Fixing Symbiotic Rhizobia with Special Reference to Indian Thar Desert. In Microbial Diversity in Ecosystem Sustainability and Biotechnological Applications: Volume 2. Soil \& Agroecosystems; Satyanarayana, T., Das, S.K., Johri, B.N., Eds.; Springer: Singapore, 2019; pp. 31-55. ISBN 9789811384875. 
25. Ahmed, M.M.E.; Iqbal Khan, M.A.; Kabir, S.; Fukuta, Y.; Obara, M. Genetic Variations of Root Development Traits under Different Concentrations and Forms of Nitrogen in Bangladeshi Rice (Oryza Sativa L.) Accessions. Soil Sci. Plant Nutr. 2020, 31-40. [CrossRef]

26. Baamrane, M.A.A.; Shehzad, W.; Ouhammou, A.; Abbad, A.; Naimi, M.; Coissac, E.; Taberlet, P.; Znari, M. Assessment of the Food Habits of the Moroccan Dorcas Gazelle in M'Sabih Talaa, West Central Morocco, Using the TrnL Approach. PLoS ONE 2012, 7, e35643. [CrossRef]

27. Tang, H.; Niu, L.; Wei, J.; Chen, X.; Chen, Y. Phosphorus Limitation Improved Salt Tolerance in Maize through Tissue Mass Density Increase, Osmolytes Accumulation, and Na+ Uptake Inhibition. Front. Plant Sci. 2019, 10. [CrossRef]

28. Meddich, A.; Jaiti, F.; Bourzik, W.; Asli, A.E.; Hafidi, M. Use of Mycorrhizal Fungi as a Strategy for Improving the Drought Tolerance in Date Palm (Phoenix Dactylifera). Sci. Hortic. 2015, 192, 468-474. [CrossRef]

29. Phillips, J.M.; Hayman, D.S. Improved Procedures for Clearing Roots and Staining Parasitic and Vesicular-Arbuscular Mycorrhizal Fungi for Rapid Assessment of Infection. Trans. Br. Mycol. Soc. 1970, 55, 158-161. [CrossRef]

30. Brundrett, M.C.; Piché, Y.; Peterson, R.L. A New Method for Observing the Morphology of Vesicular-Arbuscular Mycorrhizae. Can. J. Bot. 1984, 62, 2128-2134. [CrossRef]

31. Trouvelot, A.; Kough, J.L.; Gianinazzi-Pearson, V. Measurement of VA mycorrhizal rate of a root system estimation methods research with functional significance. In Physiological and Genetical Aspects of Mycorrhizae; INRA: Paris, France, 1986; pp. $217-221$.

32. Toubali, S.; Tahiri, A.; Anli, M.; Symanczik, S.; Boutasknit, A.; Ait-El-Mokhtar, M.; Ben-Laouane, R.; Oufdou, K.; Ait-Rahou, Y.; Ben-Ahmed, H.; et al. Physiological and Biochemical Behaviors of Date Palm Vitroplants Treated with Microbial Consortia and Compost in Response to Salt Stress. Appl. Sci. 2020, 10, 8665. [CrossRef]

33. Novozamsky, I.; Houba, V.J.G.; van Eck, R.; van Vark, W. A Novel Digestion Technique for Multi-element Plant Analysis. Commun. Soil Sci. Plant. Anal. 1983, 14, 239-248. [CrossRef]

34. Murphy, J.; Riley, J.P. A Modified Single Solution Method for the Determination of Phosphate in Natural Waters. Anal. Chim. Acta 1962, 27, 31-36. [CrossRef]

35. Rose, T.J.; Wissuwa, M. Rethinking Internal Phosphorus Utilization Efficiency. Adv. Agron. 2012, 116, $183-217$.

36. Baon, J.B.; Smith, S.E.; Alston, A.M. Mycorrhizal Responses of Barley Cultivars Differing in P Efficiency. Plant. Soil 1993, 157, 97-105. [CrossRef]

37. The R Foundation for Statistical Computing; R Version 4.0; The R Foundation: Vienna, Austria, 2020.

38. Ennaji, W.; Barakat, A.; Karaoui, I.; Baghdadi, M.E.; Arioua, A. Remote Sensing Approach to Assess Salt-Affected Soils in the North-East Part of Tadla Plain, Morocco. Geol. Ecol. Landsc. 2018, 2, 22-28. [CrossRef]

39. Delvian; Rambey, R. Effect of Salinity on Spore Germination, Hyphal Length and Root Colonization of the Arbuscular Mycorrhizal Fungi. IOP Conf. Ser. Earth Environ. Sci. 2019, 260, 012124. [CrossRef]

40. Yang, R.; Qin, Z.; Wang, J.; Xu, S.; Zhao, W.; Zhang, X.; Huang, Z. Salinity Changes Root Occupancy by Arbuscular Mycorrhizal Fungal Species. Pedobiologia 2020, 81-82, 150665. [CrossRef]

41. Beltrano, J.; Ruscitti, M.; Arango, M.C.; Ronco, M. Effects of Arbuscular Mycorrhiza Inoculation on Plant Growth, Biological and Physiological Parameters and Mineral Nutrition in Pepper Grown under Different Salinity and P Levels. J. Soil Sci. Plant Nutr. 2013, 13, 123-141. [CrossRef]

42. Porras-Soriano, A.; Soriano-Martín, M.L.; Porras-Piedra, A.; Azcón, R. Arbuscular Mycorrhizal Fungi Increased Growth, Nutrient Uptake and Tolerance to Salinity in Olive Trees under Nursery Conditions. J. Plant Physiol. 2009, 166, 1350-1359. [CrossRef]

43. Teh, C.-Y.; Shaharuddin, N.A.; Ho, C.-L.; Mahmood, M. Exogenous Proline Significantly Affects the Plant Growth and Nitrogen Assimilation Enzymes Activities in Rice (Oryza Sativa) under Salt Stress. Acta Physiol. Plant. 2016, 38, 151. [CrossRef]

44. Zhu, X.; Song, F.; Liu, S.; Liu, F. Role of Arbuscular Mycorrhiza in Alleviating Salinity Stress in Wheat (Triticum Aestivum L.) Grown Under Ambient and Elevated CO2. J. Agron. Crop. Sci. 2016, 202, 486-496. [CrossRef]

45. Cavagnaro, T.R.; Bender, S.F.; Asghari, H.R.; van der Heijden, M.G.A. The Role of Arbuscular Mycorrhizas in Reducing Soil Nutrient Loss. Trends Plant Sci. 2015, 20, 283-290. [CrossRef] 